\title{
Polylactic acid/epoxidized natural rubber biofoams: modelling and water absorption
}

\author{
Suttasinee Puttajan*, Tarinee Nampitch \\ Department of Packaging and Materials, Faculty of Agro-Industry, Kasetsart University, \\ Bangkok 10900 Thailand
}

*Corresponding author, e-mail: suttasinee.ploy@gmail.com

Received 15 Oct 2018

Accepted 25 Apr 2019

\begin{abstract}
Biofoams containing polylactic acid (PLA) and an epoxidized natural rubber (ENR-50) were prepared using various chemical foaming agents (CFA). The factors that affect the properties and characteristics of the biodegradable foams were epoxidized natural rubber (ENR)-50 and CFA contents. ENR-50 is one of the toughening agents used for blending with PLA by twin-screw extruder followed by compression moulding. Water absorption increased with increasing ENR-50 and CFA contents, due to the effect of polarity and natural hydrophilicity of the oxirane groups of ENR-50. The percentage crystallinity decreased with the addition of ENR-50 and CFA, due to the interaction between the epoxy groups of the ENR-50 and the carbonyl groups of the PLA, which makes movement more difficult and hinders the arrangement of the crystal. The addition of ENR in blend foam led to the increase of impact strength. Whereas the flexural strength of PLA/ENR foams decreased with increased ENR content. The impact strength and flexural strength of PLA/ENR-50 foams were investigated and the experimental data were analysed through SPSS and MATLAB, to optimize as well as to determine the significance of the factors affecting the impact strength and flexural strength of the foams. The parameterization of the mathematical method for different content of the initial controlled substance was achieved by fitting the mathematical model with the experimental data for impact strength and flexural strength. The 3-D curves obtained from the proposed mathematical models were plotted.
\end{abstract}

KEYWORDS: polylactic acid, epoxidized natural rubber, water absorption, foam

\section{INTRODUCTION}

Bioplastics are plastics derived from renewable biomass, also known as biopolymers, and are gaining much interest. The aim of many companies and businesses is the development of biopolymers derived from renewable and sustainable resources. The development of biopolymers is interested in the field of biopolymer blends and composites. The current development should focus on balancing product performance and environmental friendliness. The biopolymer most extensively used in research is polylactic acid (PLA), which is under continuous development ${ }^{1}$.

PLA is a biodegradable material. It is derived from sugarcane and cornstarch to substitute traditional petroleum-based plastics. The subunit of PLA, lactic acid, can be prepared by carbohydrate fermentation or chemical synthesis. Lactic acid made by the fermentation processes can be classified according to the type of bacteria used. The most recent bacteria commonly used is Lactobacilli, which gives high yields of lactic acid. In general, sources of simple sugars for bacteria are glucose and maltose obtained from corn or potato, sucrose from cane or beet sugar and lactose from cheese whey. The advantages of PLA are cost-competitive products and sustainability, but PLA has disadvantages because of its brittleness, low glass transition temperature $\left(T_{g}\right)$ and low crystallinity, which affects the formation of packaging materials ${ }^{2-4}$. Hence the properties of PLA have been improved so that it is suitable for forming into packaging. There are several ways to improve the properties of PLA, such as blending and composite preparation $^{5-7}$. One of the most popular methods is blending with a toughening agent, a rubber phase, to increase the toughness of the PLA. The rubber toughening of plastics has become an attractive field of study in polymer science and technology, as brittleness is known to be a drawback in many plastics; it can cause premature failure during application. PLA has attracted considerable attention in sectors such as packaging, cushioning, and thermal and sound insulation. Epoxidized natural rubber (ENR) has been widely used as an impact modifier or as a toughening agent for many plastics; 
in particular, it is used to increase impact strength, which deteriorates with the incorporation of other additives such as fillers and flame retardants. ENR is obtained from the modification of natural rubber via an epoxidation reaction. It also has good chemical resistance, high toughness, oil-resistance and gasbarrier properties and, a high toughness relative to natural rubber ${ }^{8}$. Foam is a popular packaging today because foams are lightweight, durable, flexible and easy to use. The characteristics of foam are better than other materials, affecting the current use foam, which is tending to increase ${ }^{9,10}$. Nowadays, the development of PLA foams could lead to the replacement of polystyrene (PS) foams because of the toxicity of PS ${ }^{11-13}$. The addition of ENR to blended foam has been employed to increase the toughness of PLA. This is the first study to investigate the water absorption behaviour and the modelling of the mechanical properties of PLA/ENR foams. The modelling study of biomaterial properties by SPSS and MATLAB is the advance research in the field of biomaterials.

\section{MATERIALS AND METHODS}

\section{Materials}

Polylactic acid (PLA) polymer 2003D in pellet form with a melt flow rate of $5-7 \mathrm{~g} / 10 \mathrm{~min}(2.16 \mathrm{~kg}$, $210^{\circ} \mathrm{C}$ ) was a commercial product from Natureworks LLC (USA). The epoxidized natural rubber (ENR-50) containing $50 \mathrm{~mol} \%$ epoxidation, was prepared by chemical modification of natural rubber, where saturation in the natural rubber is converted into epoxy groups. The chemical foaming agent (CFA) was purchased from Merck.

\section{Preparation of PLA/ENR-50 foams}

The PLA and ENR-50 were dried separately at $80^{\circ} \mathrm{C}$ and $50^{\circ} \mathrm{C}$, respectively, for $8 \mathrm{~h}$ in a hot air oven, prior to blending. The polymer blends of PLA and ENR-50 were prepared with various ENR-50 contents, ranging from $0-40 \%$ by weight. The well-mixed blends were prepared in twin-screw extruders, types LTE20-32 and LTE-20-40 (Rheocord 90, Germany) at a rotor speed of $45 \mathrm{rpm}$, at $190^{\circ} \mathrm{C}$ for $10 \mathrm{~min}$, followed by cutting into small granules. Prior to foaming, the ENR-50/PLA foams were prepared with various CFA contents, ranging from $0.5-2 \% \mathrm{wt}$ (Table 1 ). The fabricated specimens were prepared by using compression moulding (Wabash model labtech) at $210^{\circ} \mathrm{C}$ for $14 \mathrm{~min}$.
Table 1 Designation of PLA/ENR-50 foams!

\begin{tabular}{lccc}
\hline Sample name & PLA (\%wt) & ENR-50 (\%wt) & CFA (\%wt) \\
\hline P100/B0.5 & 100 & - & 0.5 \\
P100/B1.0 & 100 & - & 1.0 \\
P100/B1.5 & 100 & - & 1.5 \\
P100/B2.0 & 100 & - & 2.0 \\
P90/E10/B0.5 & 90 & 10 & 0.5 \\
P90/E10/B1.0 & 90 & 10 & 1.0 \\
P90/E10/B1.5 & 90 & 10 & 1.5 \\
P90/E10/B2.0 & 90 & 10 & 2.0 \\
P80/E20/B0.5 & 80 & 20 & 0.5 \\
P80/E20/B1.0 & 80 & 20 & 1.0 \\
P80/E20/B1.5 & 80 & 20 & 1.5 \\
P80/E20/B2.0 & 80 & 20 & 2.0 \\
P70/E30/B0.5 & 70 & 30 & 0.5 \\
P70/E30/B1.0 & 70 & 30 & 1.0 \\
P70/E30/B1.5 & 70 & 30 & 1.5 \\
P70/E30/B2.0 & 70 & 30 & 2.0 \\
P60/E40/B0.5 & 60 & 40 & 0.5 \\
P60/E40/B1.0 & 60 & 40 & 1.0 \\
P60/E40/B1.5 & 60 & 40 & 1.5 \\
P60/E40/B2.0 & 60 & 40 & 2.0 \\
\hline
\end{tabular}

$\dagger$ PLA: polylactic acid; ENR-50: epoxidized natural rubber with $50 \mathrm{~mol} \%$ epoxidation; B: chemical foaming agent.

\section{Water absorption}

The water absorption test was conducted to determine the water resistance of PLA and PLA/ENR50 foams. The dimensions of test specimens were $15 \mathrm{~mm} \times 25 \mathrm{~mm} \times 10 \mathrm{~mm}$. The test specimens were dried in a vacuum oven at $40^{\circ} \mathrm{C}$ to constant weight. The specimens were then immersed in distilled water at room temperature for $24 \mathrm{~h}$, after which the samples were withdrawn from the water and weighed. The weight gain after $24 \mathrm{~h}$ was recorded. The procedure was repeated with samples immersed for $48,72,96,120,144$, and $168 \mathrm{~h}$. The test was carried out in triplicate for each formulation and the average values reported. The percentage weight gain $\left(M_{\mathrm{t}}\right)$ after time $\mathrm{t}$ of moisture absorption was determined using equation $M_{\mathrm{t}}(\%)=\left(W_{\mathrm{w}}-W_{\mathrm{d}}\right) / W_{\mathrm{d}}$, where $W_{\mathrm{d}}$ is the initial weight of sample before immersion and $W_{\mathrm{w}}$ is the weight of sample after immersion $^{14}$.

\section{Crystallization analysis}

The crystallization of PLA foams and PLA/ENR50 foams were measured by a differential scanning calorimeter (DSC2-Mettler Toledo). Samples of weight 5-7 mg were placed in an aluminium pan and sealed tightly with an aluminium cover. For 
non-isothermal tests, the samples were first heated $\left(10^{\circ} \mathrm{C} / \mathrm{min}\right)$ from $20-200^{\circ} \mathrm{C}$. Then the samples were cooled to $0^{\circ} \mathrm{C}$ and finally heated again to $200^{\circ} \mathrm{C}$ at the same rate. The glass transition, cold crystallization, and melting temperatures denoted by $\mathrm{T}_{\mathrm{g}}$, $\mathrm{T}_{\mathrm{cc}}, \mathrm{T}_{\mathrm{m}}$, respectively, were obtained from the DSC curves. The percentage crystallinity $\left(\% \mathrm{X}_{\mathrm{c}}\right)$ was obtained from equation

$$
\% \mathrm{X}_{\mathrm{c}}=\frac{\left(\Delta H_{\mathrm{m}}-\left|\Delta H_{\mathrm{c}}\right|\right)}{93.6} \times \frac{100}{w},
$$

where $\Delta H_{\mathrm{m}}$ is melting enthalpy, $\Delta H_{\mathrm{c}}$ is crystallization enthalpy, the constant $93.6 \mathrm{~J} / \mathrm{g}$ is melting enthalpy of $100 \%$ crystallization, and $w$ is the weight fraction of PLA contained in the blend foams.

\section{Model development for properties}

The fitting of model equations for determination of mechanical properties was by Statistical Package for the Social Sciences (SPSS 19, IBM, USA) and MATLAB R2018a (MathWorks, USA). The best model for describing the experimental data was confirmed using the correlation coefficient $\left(R^{2}\right)$ to evaluate the error analysis. For this purpose, the modelling of compressive properties and flexural strength were obtained by demonstrating the best fit for mechanical properties, following a model

$$
\begin{aligned}
Y & =C+A\left(X_{1}\right)-B\left(X_{2}\right) \\
Y_{1} & =D-E\left(X_{1}\right)-F\left(X_{2}\right)
\end{aligned}
$$

where $Y$ in Eq. (1) is impact strength, $X_{1}$ is ENR content, $X_{2}$ is CFA content, and $A, B, C$ are constants. Eq. (2) was used to determine the flexural strength $\left(Y_{1}\right)$. The three independent constants, $D, E, F$ were found to be sufficient to make a reasonable fit to most data. The curve-fitting was conducted to predict the properties with various material contents.

\section{RESULTS AND DISCUSSION}

\section{The effect of ENR-50 content on water absorption of PLA/ENR-50 foams}

Water absorption by polymers takes place at the surface of the material. When water absorption is saturated, the water penetrates into the polymer ${ }^{14-16}$. Water absorption values of PLA/ENR50 foams with compositions of PLA of $100-60 \%$ by weight, ENR-50 of 0-40\% by weight and CFA at 0.5$2 \%$ by weight are shown (Fig. 1 ). The results show that water absorption is likely to increase with the addition of ENR-50, that effect being due to the polar and naturally hydrophilic oxirane groups of ENR50. Polarity and hydrophilicity of the polymer will encourage hydrogen bonding with water ${ }^{17}$. Hence when mixed with PLA, which is already hydrophilic, the water absorption of PLA/ENR-50 foams tends to increase compared to PLA foams.

\section{The effect of CFA content on water absorption of PLA/ENR-50 foams}

Firstly, the water absorption of polymers takes place at the surface of the material. When the water absorption is saturated, the water will penetrate into the polymer. The water absorption is regulated by hydrophilic nature of the substance ${ }^{14-16}$. The water absorption values of PLA/ENR-50 foams at various contents of PLA, ENR, and foaming agent as $100-60 \%$ by weight, $0-40 \%$ by weight and $0.5-$ $2 \%$ by weight, respectively, are shown (Fig. 2 ). The results of the experiment exhibited that the water absorption tends to increase with the increment of ENR-50 content because of the effect of polarity and hydrophilicity obtained from oxirane group of ENR50 . The polarity and hydrophilicity of polymer will encourage the hydrogen bonding between ENR and water molecules ${ }^{17}$. Then the addition of ENR in PLA foams led to the higher percentage of water absorption compared with pure PLA foams because of the hydrophilicity of PLA. The increase in CFA in the foam blend tends to increase the percentage of water absorption as the surface area in contact with water tends to increase because the heating of agents in the blend causes the breakdown into $\mathrm{CO}_{2}$ gas in the foam ${ }^{18}$. The $\mathrm{CO}_{2}$ gas penetrates into the polymer matrix and forms a gas during polymer processing. The gas forms minute cells or bubbles within the polymer, resulting in a foamed or porous structure. After saturation, the $\mathrm{CO}_{2}$ disappears, causing the voids in the polymer, and the surface area in contact with water, to increase ${ }^{15,19,20}$.

\section{The effect of foaming agent on crystallinity of PLA foam}

The effect of foaming agent on the crystallinity of the PLA unfoam and PLA foams (Table 2) is investigated. The results reveal that percentage crystallinity $\left(\% \mathrm{X}_{\mathrm{c}}\right)$, glass transition temperature $\left(\mathrm{T}_{\mathrm{g}}\right)$, and melting temperature $\left(\mathrm{T}_{\mathrm{m}}\right)$ of PLA foams are $0.43,56.96$, and $151^{\circ} \mathrm{C}$, respectively. When a CFA is added to the PLA foams, percentage crystallinity, glass transition temperature, and melting temperature of PLA foams were changed depending on the amount of CFA added. The results show that 

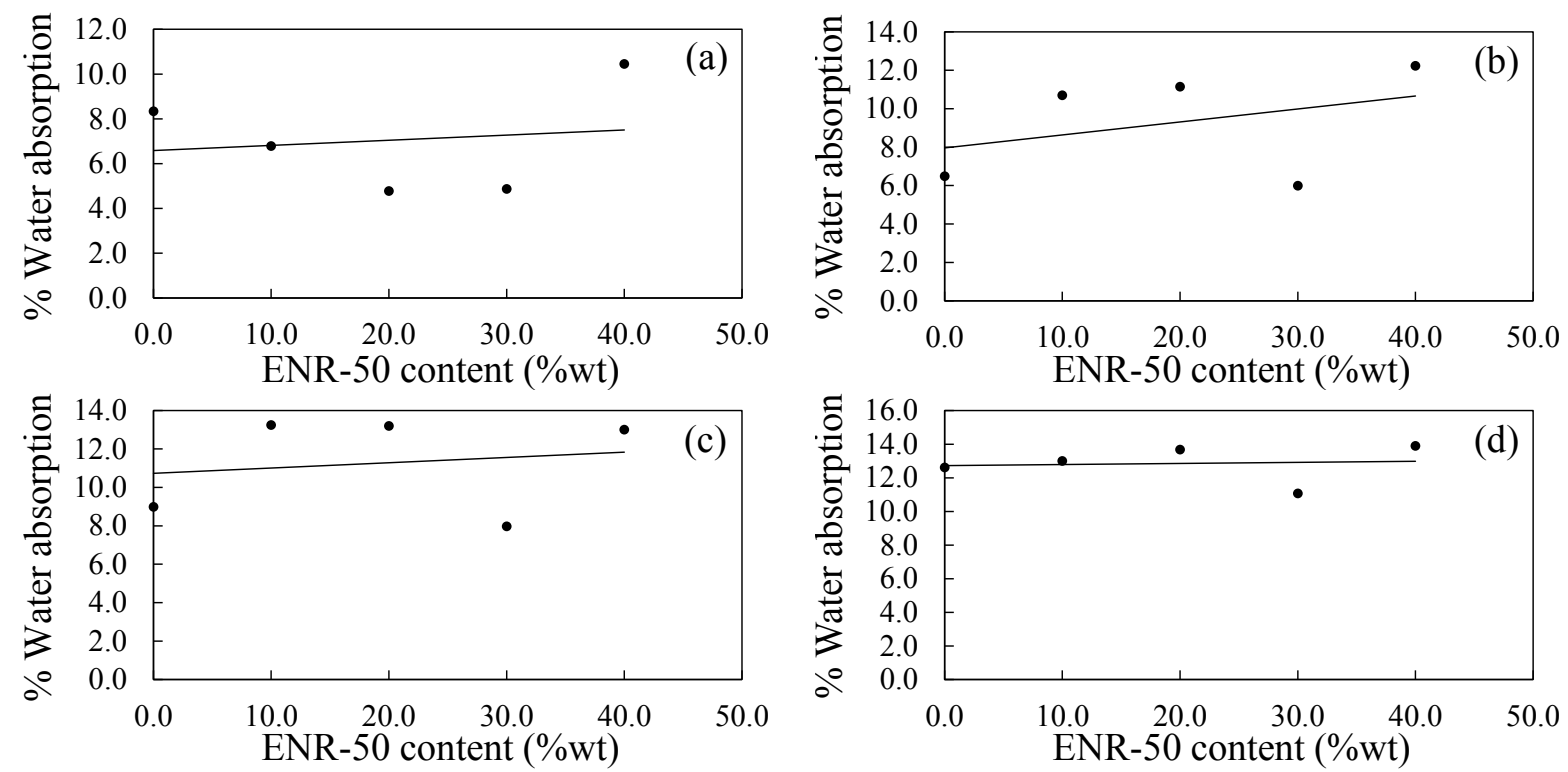

Fig. 1 Water absorption values of PLA/ENR-50 foams with CFA content ranging from 0.5-2 \%wt; (a) $0.5 \%$ wt, (b) 1.0 \%wt, (c) $1.5 \% w t$, (d) $2.0 \% w t$.
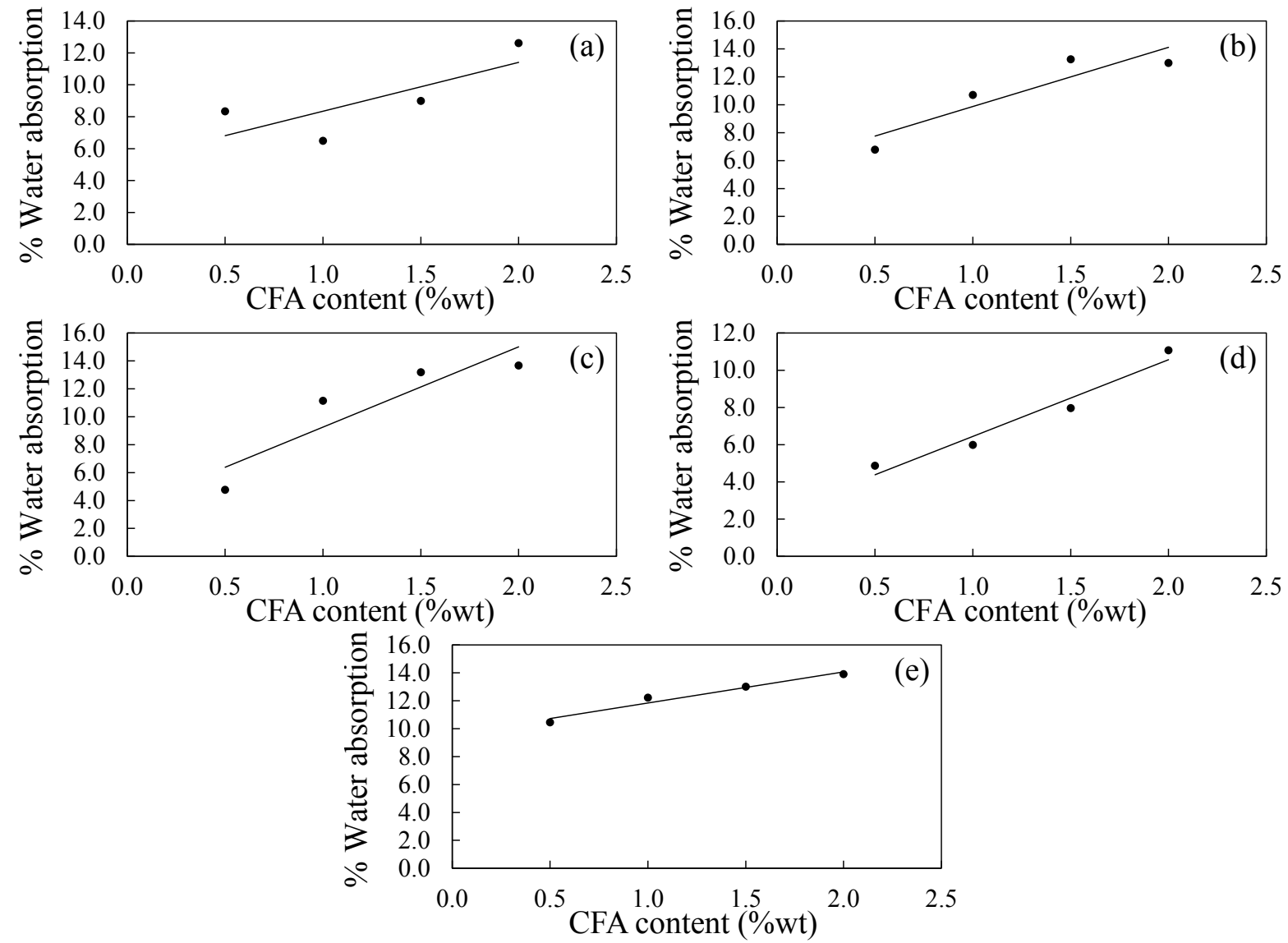

Fig. 2 Water absorption values of PLA/ENR-50 foams; (a) P100, (b) P90/E10, (c) P80/E20, (d) P70/E30, (e) P60/E40. 
Table 2 The thermal properties of PLA unfoam and PLA foams with various CFA contents obtained from second heating DSC scans.

\begin{tabular}{lcccc}
\hline Sample & $\mathrm{T}_{\mathrm{g}}\left({ }^{\circ} \mathrm{C}\right)$ & $\mathrm{T}_{\mathrm{cc}}\left({ }^{\circ} \mathrm{C}\right)$ & $\mathrm{T}_{\mathrm{m}}\left({ }^{\circ} \mathrm{C}\right)$ & $\% \mathrm{X}_{\mathrm{c}}$ \\
\hline PLA & 56.96 & 121.17 & 151.00 & 0.43 \\
P100/B0.5 & 56.73 & 126.67 & 150.17 & 0.41 \\
P100/B1.0 & 48.82 & 115.83 & 146.17 & 0.40 \\
P100/B1.5 & 41.65 & 110.67 & 144.83 & 0.32 \\
P100/B2.0 & 46.99 & 115.17 & 146.67 & 0.21 \\
\hline
\end{tabular}

percentage crystallinity tends to decrease with the increase of CFA content, whereas glass transition temperature and melting temperature tend to decrease, as the CFA in the foam blend is heated and breaks down to release $\mathrm{CO}_{2}$. This is a small molecule that penetrates into the polymer melt matrix and generate $\mathrm{CO}_{2}$ bubbles. The $\mathrm{CO}_{2}$ is a plasticizer that improves the movement of the PLA molecular chain, which makes it easier to align the molecular chain in lattice crystals, resulting in lower $\mathrm{T}_{\mathrm{g}}$ and $\mathrm{T}_{\mathrm{m}}$ values ${ }^{9} \cdot \mathrm{CO}_{2}$ could diffuse into biaxial stretching, which occurs during the expansion and growth of the cell, causing the percentage crystallinity to tend to increase due to the stress of decreased crystallization $^{21-23}$.

The results of DSC tests exhibited in the thermograms (Fig. 3) show the second heating scans of unfoam and PLA foams. During DSC second heating scan, the cold crystallization occurs.

\section{The effect of ENR-50 content on crystallinity of PLA/ENR-50 foams}

The thermal properties of PLA/ENR foams with various CFA contents at $0.5-2 \%$ wt are shown (Table 3 ). When ENR-50 is added to the foam blend, hydrogen bonding is believed to occur because of the interaction between the epoxy groups in ENR-50 and the carbonyl groups in PLA. This interaction affects the movement of the chain structure, making it more difficult and hindering the arrangement of the crystal, resulting in a decrease glass transition temperature and melting temperature. In addition, the PLA foams with ENR exhibit low $\mathrm{T}_{\mathrm{cc}}$ values in second heating DSC scans as compared with the neat PLA foams. This result may be due to the fast nucleation process induced by $\mathrm{ENR}^{24-26}$.

\section{Mechanical behaviour}

The effect of rubber and foaming agent content on the mechanical behaviour of PLA/ENR-50 foams was investigated (Figs. 4 and 5). In this work, linear
Table 3 The thermal properties of PLA/ENR foams with various CFA contents obtained from second heating DSC scans.

\begin{tabular}{lcccc}
\hline Sample & $\mathrm{T}_{g}\left({ }^{\circ} \mathrm{C}\right)$ & $\mathrm{T}_{\mathrm{cc}}\left({ }^{\circ} \mathrm{C}\right)$ & $\mathrm{T}_{\mathrm{m}}\left({ }^{\circ} \mathrm{C}\right)$ & $\% \mathrm{X}_{\mathrm{c}}$ \\
\hline P90/E10/B0.5 & 38.95 & 111.83 & 141.50 & 0.50 \\
P90/E10/B1.0 & 38.98 & 111.33 & 141.00 & 0.49 \\
P90/E10/B1.5 & 54.77 & 126.67 & 149.83 & 0.43 \\
P90/E10/B2.0 & 39.78 & 104.67 & 143.67 & 0.39 \\
P80/E20/B0.5 & 40.94 & 109.83 & 143.33 & 0.36 \\
P80/E20/B1.0 & 35.17 & 106.33 & 138.83 & 0.33 \\
P80/E20/B1.5 & 41.77 & 107.83 & 142.67 & 0.39 \\
P80/E20/B2.0 & 42.76 & 109.17 & 142.50 & 0.32 \\
P70/E30/B0.5 & 36.40 & 104.33 & 139.33 & 0.31 \\
P70/E30/B1.0 & 36.15 & 107.00 & 139.00 & 0.27 \\
P70/E30/B1.5 & 36.11 & 107.67 & 137.33 & 0.26 \\
P70/E30/B2.0 & 34.10 & 107.17 & 136.83 & 0.23 \\
P60/E40/B0.5 & 37.97 & 102.17 & 139.50 & 0.16 \\
P60/E40/B1.0 & 32.36 & 103.33 & 135.00 & 0.14 \\
P60/E40/B1.5 & 33.90 & 102.50 & 137.00 & 0.12 \\
P60/E40/B2.0 & 42.39 & 109.33 & 141.67 & 0.09 \\
\hline
\end{tabular}

regression analysis by SPSS was used to generate the mathematical model in order to predict mechanical types of behaviour such as impact strength and flexural strength of biodegradable foams composed of polylactic acid (PLA), epoxidized natural rubber (ENR-50) and chemical foaming agent (CFA) ${ }^{27}$. The use of SPSS was employed to analyse experimental data from a fixed model.

The model results, equations (3) and (4), were developed from linear regression analysis of the experimental data used, to derive a mathematical expression. The adjusted $R^{2}$ of the model for impact strength was 0.33 , where $Y$ is impact strength, $X_{1}$ is ENR content, and $X_{2}$ is CFA content.

$$
Y=0.294+0.005 X_{1}-0.006 X_{2}
$$

The relationship between impact strength and two factors of ENR-50 content and CFA content, which was plotted by MATLAB was employed to produce 3-D curves (Fig. 4).

The adjusted $R^{2}$ of the model for flexural strength was 0.677 . The model for flexural strength is

$$
Y_{1}=14.723-0.292 X_{1}-1.522 X_{2} \text {, }
$$

where $Y_{1}$ is flexural strength, $X_{1}$ is ENR content, and $X_{2}$ is CFA content. The relationship between flexural strength and the two factors of ENR content and CFA content was plotted by MATLAB (Fig. 5). 

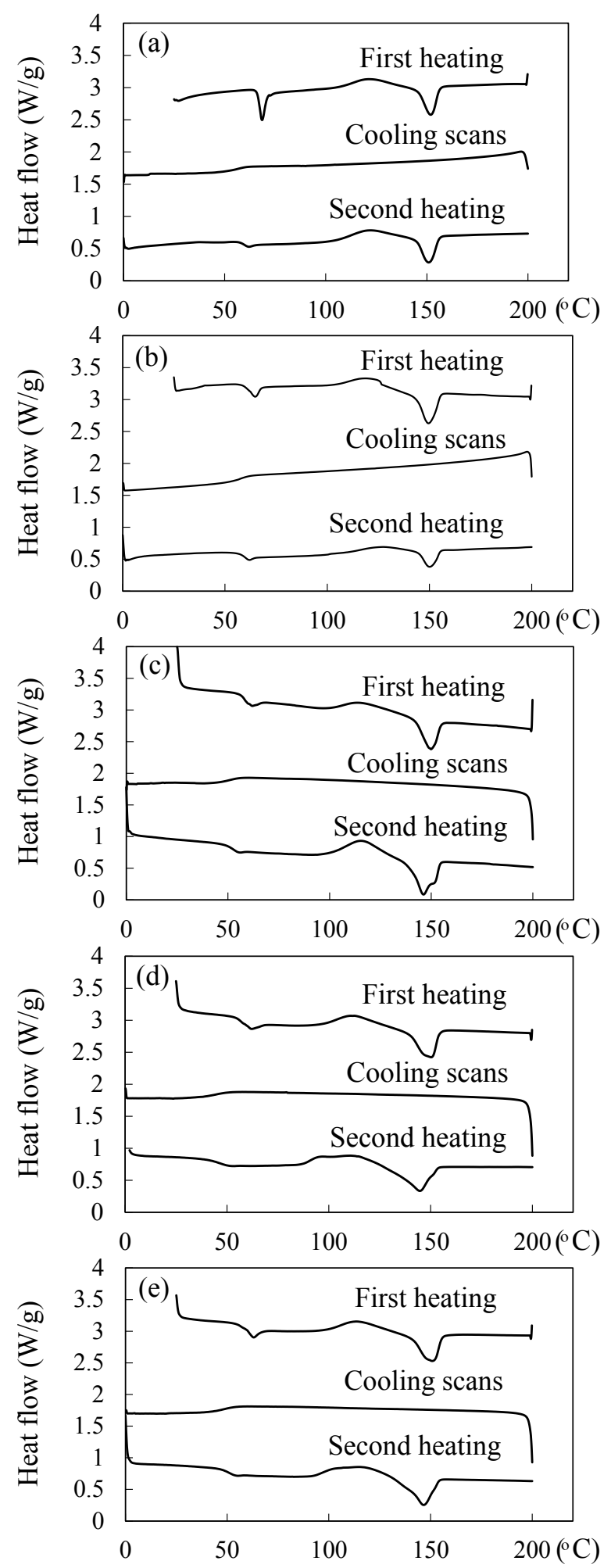

Fig. 3 DSC thermograms of PLA foams with CFA content ranging from $0-2 \% w t ;$ (a) $0 \% w t$, (b) $0.5 \% w t$, (c) 1.0 \%wt, (d) $1.5 \% w t$, (e) $2.0 \% w t$.

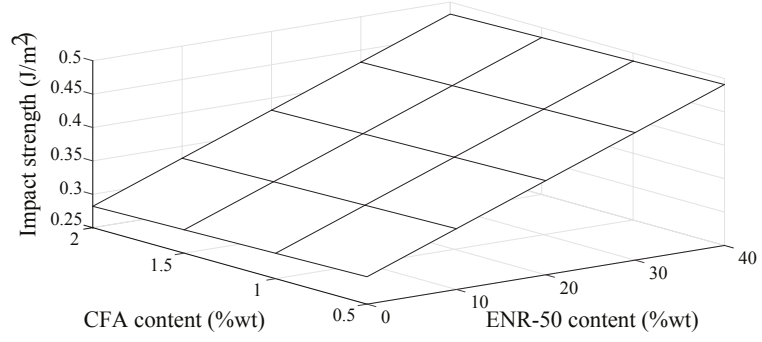

Fig. 4 3-D curves of impact strength of PLA/ENR-50 foams at various CFA and ENR-50 contents.

\section{CONCLUSIONS}

In this study, the water absorption of biofoams containing PLA and ENR increased with increases in ENR-50 and CFA content, because of the effect of polarity and natural hydrophilicity of the oxirane groups of ENR-50. The polarity and hydrophilicity of the polymer will encourage the occurrence of hydrogen bonding between the ENR and water molecules and the increase in surface area in contact with water of the blended foam. The percentage crystallinity decreased with increasing ENR-50 and CFA content. The impact strength and flexural strength of PLA/ENR-50 foams were investigated and SPSS 19 and MATLAB R2018a were employed to analyse the experimental data, to determine the significance of the factors affecting the impact strength and flexural strength of PLA/ENR-50 foams. The introduction of ENR in blend foam affected the increase in impact strength and decrease in flexural strength.

Acknowledgements: The authors would like to thank the Graduate School, Kasetsart University for financial support. We also acknowledge the Mettler Toledo, Thailand and Faculty of Agro-Industry for supporting equipment and facilities, respectively.

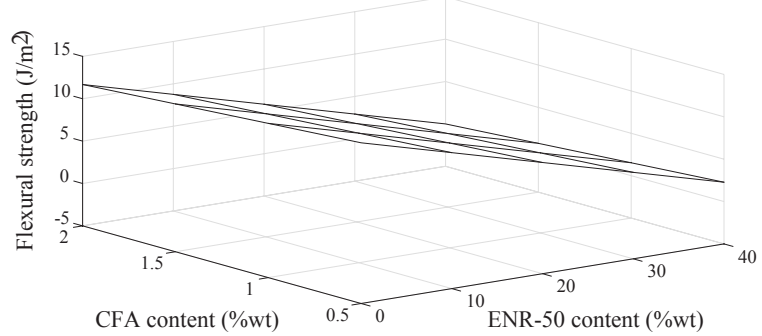

Fig. 5 3-D curves of flexural strength of PLA/ENR-50 foams at various CFA and ENR-50 contents. 


\section{REFERENCES}

1. Nagarajan V, Mohanty AV, Misra M (2016) Perspective on polylactic acid (PLA) based sustainable materials for durable applications: focus on toughness and heat resistance. ACS Sustainable Chem Eng 4, 2899-916.

2. Auras R, Harte B, Selke S (2004) An overview of polylactides as packaging materials. Macromol Biosci 4, 835-64.

3. Nampoothiri KM, Nair NR, John RP (2010) An overview of the recent developments in polylactide (PLA) research. Bioresour Technol 101, 8493-501.

4. Rasal RM, Janorkar AV, Hirt DE (2010) Poly (lactic acid) modifications. Prog Polym Sci 35, 338-56.

5. Lim LT, Auras R, Rubino M (2008) Processing technologies for poly(lactic acid). Prog Polym Sci 33 , 820-52.

6. Dechatiwong Na Ayutthaya W, Poompradub S (2014), Thermal and mechanical properties of poly(lactic acid)/natural rubber blend using epoxidized natural rubber and poly(methyl methacrylate) as co-compatibilizers. Macromol Res 22, 686-92.

7. Akbari A, Jawaid M, Hassan A, Balakrishnan H (2014) Epoxidized natural rubber toughened polylactic acid/talc composites: mechanical, thermal, and morphological properties. J Compos Mater 48, 769-81.

8. Tanjung FA, Hassan A, Hasan M (2015) Use of epoxidized natural rubber as a toughening agents in plastics. J Appl Polym Sci 132, 42270-9.

9. Kasturirangan A, Koh CA, Teja AS (2011) Glasstransition temperatures in $\mathrm{CO}_{2}+$ polymer systems: modeling and experiment. Ind Eng Chem Res 50, 158-62.

10. Ouipanich S, Kaisone T, Hanthanon P, Wiphanurat C, Thongjun Y, Nampitch T (2017) Effect of the citric acid as foaming agent on the compressive properties and morphology of PLA/ENR blend foams. Appl Mech Mater 873, 95-100.

11. Nofar M, Park CB (2014) Poly (lactic acid) foaming. Prog Polym Sci 39, 1721-41.

12. Kaisone T, Harnkarnsujarit N, Leejarkpai T, Nampitch $T$ (2016) Mechanical and thermal properties of toughened PLA composite foams with modified coconut fiber. Appl Mech Mater 851, 179-85.

13. Tiwary P, Park CB, Kontopoulou M (2017) Transition from microcell-nanocellular PLA foams by controlling viscosity, branching and crystallization. Eur Polym J 91, 283-96.

14. Tham WL, Chow WS, Poh BT, Ishak ZAM (2016) Poly(lactic acid)/halloysite nanotube nanocomposites with high impact strength and water barrier properties. J Compos Mater 50, 3925-34.

15. Yew GH, Mohd Yusof AM, Mohd Ishak ZA, Ishiaku US (2005) Water absorption and enzymatic degradation of poly(lactic acid)/rice starch composites. Polym
Degrad Stab 90, 488-500.

16. Wahit MU, Hassan A, Ibrahim AN, Zawawi NA, Kunasegeran K (2015) Mechanical, thermal and chemical resistance of epoxidized natural rubber toughened polylactic acid blends. Sains Malaysiana 44, 1615-23.

17. Preechawong D, Peesan M, Supaphol P, Rujiravanit $R$ (2004) Characterization of starch/poly $(\varepsilon$ caprolactone) hybrid foams. Polym Test 23, 651-7.

18. Matuana LM, Faruk O, Diaz CA (2009) Cell morphology of extrusion foamed poly(lactic acid) using endothermic chemical foaming agent. Bioresour Technol 100, 5947-54.

19. Li Q, Matuana LM (2003) Foam extrusion of high density polyethylene/wood-flour composites using chemical foaming agents. J Appl Polym Sci 88, 3139-50.

20. Zimmermann MVG, Brambilla VC, Brandalise RN, Zattera AJ (2013) Observations of the effects of different chemical foaming agents on the degradation of poly(lactic acid) foams in simulated soil. Mater Res 16, 1266-73.

21. Nofar M, Zhu W, Park CB (2012) Effect of dissolved $\mathrm{CO}_{2}$ on the crystallization behavior of linear and branched PLA. Polymer 53, 3341-53.

22. Costeux S, Jeon H, Bunker S, Khan I (2012) Nanocellular foams from acrylic polymers: experiments and modeling. In: 10th International Conference on Foam Materials \& Technology (SPE FOAMS 2012), Barcelona, Spain, pp. 1-6.

23. Wang L, Lee RE, Wang G, Chu RKM, Zhao J, Park CB (2017) Use of stereocomplex crystallites for fully-biobased microcellular low-density poly(lactic acid) foams for green packaging. Chem Eng J 327, 1151-62.

24. Wang Y, Chen K, Xu C, Chen Y (2015) Supertoughened biobased poly(lactic acid)-epoxidized natural rubber thermoplastic vulcanizates: fabrication, cocontinuous phase structure, interfacial in situ compatibilization, and toughening mechanism. $J$ Phys Chem B 119, 12138-46.

25. Julien JM, Quantin JC, Bénézet JC, Bergeret A, Lacrampe MF, Krawczak P (2015) Chemical foaming extrusion of poly(lactic acid) with chain extenders: physical and morphological characterizations. Eur Polym J 67, 40-9.

26. Cosme JGL, Silva VM, Nunes RRC, Picciani PHS (2016) Development of biobased poly(lactic acid)/epoxidized natural rubber blends processed by electrospinning: morphological, structural and thermal properties. Mater Sci Appl 7, 210-9.

27. Puttajan S, Nampitch T (2018) Impact strength and flexural properties of biodegradable foams containing polylactic acid and epoxidized natural rubber. In: Proceedings of the 9th Rajamangala University of Technology International Conference, Thailand, 149-58. 